\title{
Evaluation of Some Plant Extracts against Adults of the Saw-toothed Grain Beetle, Oryzaephilus surinamensis (Linn.) (Coleoptera: Silvanidae)
}

\author{
Rogeia Elmahi Haj Alawad Yousif ${ }^{1}$, Awad Khalafalla Taha, ${ }^{2, *}$ \\ ${ }^{1}$ Plant Protection Directorate, Sudan \\ ${ }^{2}$ College of Agricultural Studies- Shambat, Sudan University of Science and Technology, Sudan
}

Copyright $\odot 2016$ by authors, all rights reserved. Authors agree that this article remains permanently open access under the terms of the Creative Commons Attribution License 4.0 International License.

\begin{abstract}
Laboratory studies were carried out to determine the effects of three plant extracts on adults of the saw-toothed grain beetle Oryzaephilus surinamensis. The three plants were Usher (Calotropis procera), Argel (Solenostemma argel) and Datura (Datura stramonium). Results revealed that at the three doses applied (5\%, 10\% and $15 \%$ ) extracts of the three plants tested showed some potential insecticidal effects on the adults of $O$. surinamensis, with the $C$. procera (Ethanol) the most effective one. In addition, all extracts showed high repellency action against the pest.
\end{abstract}

Keywords Saw-toothed Grain Beetle, Usher (C.Procera), Argel (S.Argel)

\section{Introduction}

Synthetic pesticides have traditionally been used as grain protectants across the globe. They have great potential in pest control, especially in terms of efficacy during emergency situations. However, chemicals used for controlling store pests have resulted in many problems, such as toxicity of the treated food grains, ultimately creating some sanitary and phytosanitary problems and lethal effects on non -target organisms (Ajayi and Lale, [5]). Other problems include poor knowledge of application cost, genetic resistance and hazards to health.

At present, alternative strategies have included the search for new types of pesticides of botanical origin, which are often effective against a limited number of specific target species, are biodegradable into nontoxic products and are suitable for use in integrated pest management programs (Adedire and Ajaji [2]; Akinkurolere, etal. [6]). Historically, the plant materials have been in use longer than any other group, with the possible exception of Sulphur. Tobacco, Pyrethrum, Derris, Quassia, Camphor and Turpentine were some of the more important plant products in use before the organized search for insecticides began (Sousa et al. [20].

In Sudan, many studies were made during the last decades to test effects of some plant materials against various agricultural and stored product pests (for example, Siddig [19]; Ahmed [3]; Sidahmed [18]; Bakhiet and Taha, [8] and Yousif and Satti [21]). In the same context, the present study was carried out, under laboratory condition, to investigate the effects of three plants (e.g., Usher, Calotropis procera (Ait), Argel, Solenostemma argel (Del) and Datura, Datura stramonium L, for controlling the main dates' store pest found, the Saw-toothed grain beetle, Oryzaephilus surinamensis (Linnaeus).

\section{Materials and Methods}

\section{Mass Culture of the Insect}

The Saw-toothed grain beetle adults were collected from infested dates brought from different stores and reared in the laboratory. The collected adults were distributed in a large number of glass jars containing clean, undamaged dates and each is tightly covered with a muslin cloth.

\section{Preparation of the Plant Materials}

Samples of Usher and Datura leaves were collected from the fields around the College of Agricultural Studies in Shambat. Samples of Argel leaves were bought fresh from Omdurman Market.

\section{Preparation of Plant Powders}

The preparation was based on the method by Ascher [7]. The plant samples were kept in a dark room for almost 3-5 days until completely dry. Then the samples were crushed firstly by hand and blended by an electric blender to powders, and each sample was kept in a tightly closed glass 
jar.

\section{Preparation of Plant Aqueous Extracts:}

The aqueous extracts of Usher, Argel and Datura leaves were prepared by adding 5,10 and $15 \mathrm{gms}$ of the powder to 95, 90 and $85 \mathrm{ml}$ of distilled water in conical flasks, respectively. The mixtures were thoroughly shaken by hand for ten minutes and kept in the laboratory for $24 \mathrm{hrs}$ at room temperature, and then the mixtures were filtered using filter papers. The extracts were kept in cleaned flasks and used for the mortality experiments.

\section{Soxhlet Extraction}

The soxhlet extraction was made for the three plants. A sample of 20 grams of the fine powder of each plant (Usher, Argel and Datura) were weighed and placed in the extraction tube, and the tube was placed in a flask containing ethanol $(200 \mathrm{ml})$ in soxhlet apparatus. The soxhlet was powered for 6 hours to extract the active ingredients and then the flask was left under room temperature for evaporation of the ethanol. The extract was used after 7 days in the experiments. The ethanol extracts of Usher, Argel and Datura were prepared by adding 5,10 and $15 \mathrm{ml}$ of the active ingredients to 95, 90 and $85 \mathrm{ml}$ of Ethyl Alcohol to give 5,10 and $15 \%$ concentrations, respectively.

\section{Experiment 1:}

Three glass jars, each containing $20 \mathrm{~g}$ of dates and 20 adult insects, were treated with three different Weights of powder $(5,10$ and $15 \mathrm{~g})$ of each of the three plants, and a fourth glass was used as control. The percentage mortality of adults was taken twice after 24 and 48 hours.

\section{Experiment 2:}

Three glass jars, each contained $20 \mathrm{~g}$ of dates and 20 adult insects, were treated with three different concentrations $(5 \%, 10 \%$ and $15 \%)$ of the aqueous extract of each of the three plants, and a fourth glass was used as control, and the adult mortality was measured after 24 and 48 hours.

\section{Experiment 3:}

Three glass jars, each contained $20 \mathrm{~g}$ of dates and 20 adult insects, were treated with three different concentrations $(5 \%, 10 \%$ and $15 \%)$ of the ethanol extract of each of the three plants, and a fourth glass was used as control. The adult mortality was also recorded after 24 and 48 hours.

In all experiments, three replicates were used with each of the concentrations applied.

\section{Statistical Analysis}

The experiments were assigned in a completely Randomized Design (CRD). Data were subjected to analysis of variance (ANOVA), and treatment means were separated using the Least Significant Difference (LSD) at 5\% level of probability.

\section{Results}

\subsection{Effects of Usher, Argel and Datura Leaves Powder Extracts on Adults of the Saw-toothed Grain Beetle}

The results of all experiments are shown in Tables (1-3). In Table (1), the tested leaves powder's extracts of the 3 plants showed somewhat increased numbers of adult mortality of the saw-toothed grain beetle, compared with the controls. The highest concentration (15\%) of Usher and Argel showed the same level of adult mortality, (26.7\%) after 48 hours. The lowest effect at the same period was recorded by Datura concentration $5 \mathrm{~g}$, with an adult mortality of $(15 \%)$ in the second day.

Table 1. Effects of Usher, Argel and Datura leaves powder extracts on adults of the Saw-toothed grain beetle.

\begin{tabular}{|c|c|c|c|}
\hline Treatments & Concentrations & Means (24hrs) & Means (48 hrs) \\
\hline \multirow{3}{*}{ Usher } & $5 \%$ & $16.7^{\text {bcde }}$ & $25.0^{\mathrm{ab}}$ \\
\hline & $10 \%$ & $21.7^{\mathrm{abc}}$ & $25.0^{\mathrm{ab}}$ \\
\hline & $15 \%$ & $23.3^{\mathrm{abc}}$ & $26.7^{\mathrm{a}}$ \\
\hline \multirow{3}{*}{ Argel } & $5 \%$ & $15.0^{\text {cdef }}$ & $23.3^{\mathrm{abc}}$ \\
\hline & $10 \%$ & $10.0^{\text {efg }}$ & $20.0^{\mathrm{abcd}}$ \\
\hline & $15 \%$ & $18.3^{\text {abcde }}$ & $26.7^{\mathrm{a}}$ \\
\hline \multirow{3}{*}{ Datura } & $5 \%$ & $7.5^{\mathrm{fg}}$ & $15.0^{\text {cdef }}$ \\
\hline & $10 \%$ & $11.7^{\mathrm{def}}$ & $16.7^{\text {bdde }}$ \\
\hline & $15 \%$ & $11.7^{\mathrm{def}}$ & $21.7^{\mathrm{abc}}$ \\
\hline Control & $0 \%$ & $2.5^{\mathrm{g}}$ & $2.5^{\mathrm{g}}$ \\
\hline $\mathrm{SE} \pm$ & \multicolumn{3}{|c|}{4.2} \\
\hline $\mathrm{CV} \%$ & \multicolumn{3}{|c|}{30.1} \\
\hline LSD & \multicolumn{3}{|c|}{8.5} \\
\hline
\end{tabular}

*Means followed by the same letter(s) in the same column are not significantly different at $(\mathrm{p}=0.05)$. 


\subsection{Effects of Usher, Argel and Datura Water Extracts on Adults of the Saw-toothed Grain Beetle}

In addition, results of Table (2) showed that, the water extracts of the plants caused less insecticidal effects on the adult beetles. Significant differences were recorded in percentages of adult mortality between the different concentrations; however, there was a significant difference between each treatment and the control. The highest percentage of adult mortality was recorded by Usher concentration $15 \%$ after 48 hours, while the lowest mean mortality was recorded by Argel 5\%.

\subsection{Effects of Usher, Argel and Datura Ethanol Extracts on Adults of the Saw-toothed Grain Beetle}

Also, the results in Table (3) indicated that, Ethanol extracts of the plants caused increased adult mortality at the 3 concentrations, compared with the control. Almost all concentrations of the three plants showed similar effects on the adult beetles after 48 hours, with those of Usher and Argel causing higher percentage of adult mortality.

Table 2. Effects of Usher, Argel and Datura aqueous extracts on adults of the Saw-toothed grain beetle

\begin{tabular}{|c|c|c|c|}
\hline Treatments & Concentrations & Means (24hrs) & Means (48 hrs) \\
\hline \multirow{3}{*}{ Usher } & $5 \%$ & $12.5^{\mathrm{de}}$ & $15.0^{\text {cde }}$ \\
\hline & $10 \%$ & $13.3^{\mathrm{de}}$ & $21.7^{\mathrm{ab}}$ \\
\hline & $15 \%$ & $16.7^{\mathrm{bcd}}$ & $25.0^{\mathrm{a}}$ \\
\hline \multirow{3}{*}{ Argel } & $5 \%$ & $9.2^{\mathrm{e}}$ & $13.3^{\text {de }}$ \\
\hline & $10 \%$ & $10.0^{\mathrm{e}}$ & $15.0^{\text {cde }}$ \\
\hline & $15 \%$ & $16.7^{\mathrm{bcd}}$ & $21.7^{\mathrm{ab}}$ \\
\hline \multirow{3}{*}{ Datura } & $5 \%$ & $10.0^{\mathrm{e}}$ & $16.7^{\mathrm{bcd}}$ \\
\hline & $10 \%$ & $15.0^{\text {cde }}$ & $16.7^{\mathrm{bcd}}$ \\
\hline & $15 \%$ & $13.3^{\mathrm{de}}$ & $20.0^{\mathrm{abc}}$ \\
\hline Control & $0 \%$ & $2.5^{\mathrm{f}}$ & $2.5^{\mathrm{f}}$ \\
\hline $\mathrm{SE} \pm$ & \multicolumn{3}{|c|}{2.9} \\
\hline $\mathrm{CV} \%$ & \multicolumn{3}{|c|}{25.07} \\
\hline LSD & \multicolumn{3}{|c|}{5.9} \\
\hline
\end{tabular}

*Means followed by the same letter(s) in the same column are not significantly different at ( $\mathrm{p}=0.05)$.

Table 3. Effects of Usher, Argel and Datura ethanol extracts on of the Saw-toothed grain beetle.

\begin{tabular}{|c|c|c|c|}
\hline Treatments & Concentrations & Means (24hrs) & Means (48 hrs) \\
\hline \multirow{3}{*}{ Usher } & $5 \%$ & $20.0^{\mathrm{bc}}$ & $30.0^{\mathrm{a}}$ \\
\hline & $10 \%$ & $21.7^{\mathrm{b}}$ & $28.3^{\mathrm{a}}$ \\
\hline & $15 \%$ & $26.7^{\mathrm{a}}$ & $30.0^{\mathrm{a}}$ \\
\hline \multirow{3}{*}{ Argel } & $5 \%$ & $16.7^{\text {cd }}$ & $26.7^{\mathrm{a}}$ \\
\hline & $10 \%$ & $16.7^{\mathrm{cd}}$ & $30.0^{\mathrm{a}}$ \\
\hline & $15 \%$ & $16.7^{\mathrm{cd}}$ & $28.3^{\mathrm{a}}$ \\
\hline \multirow{3}{*}{ Datura } & $5 \%$ & $13.3^{\mathrm{d}}$ & $20.0^{\mathrm{bc}}$ \\
\hline & $10 \%$ & $18.3^{\mathrm{bc}}$ & $26.7^{\mathrm{a}}$ \\
\hline & $15 \%$ & $20.0^{\mathrm{bc}}$ & $26.7^{\mathrm{a}}$ \\
\hline Control & $0 \%$ & $2.5^{\mathrm{e}}$ & $2.5 \mathrm{e}$ \\
\hline $\mathrm{SE} \pm$ & \multicolumn{3}{|c|}{2.2} \\
\hline $\mathrm{CV} \%$ & \multicolumn{3}{|c|}{12.8} \\
\hline LSD & \multicolumn{3}{|c|}{4.5} \\
\hline
\end{tabular}

*Means followed by the same letter(s) in the same Colum are not significantly different at $(\mathrm{p}=0.05)$. 


\section{Discussion}

The use of synthetic pesticides to control insect pests has created many problems and increased the serious hazards encountered by man and animals due to environmental pollutions, destruction of beneficial insects, natural enemies and non - target organisms. This is in addition to the development of insect resistance and the high cost of pesticides. To combat these problems, there was an urgent need for safe but effective, biodegradable pesticides with no toxic effects on non-target organisms. This has created a world-wide interest in research particularly the use of plant extracts as alternative to synthetic chemicals. Many plant extracts may be used for protection of stored product pests as they constitute a rich source of bioactive chemicals. (Kim et al. [11]).

The present study was carried out to investigate the insecticidal effects of three plants naturally grown in Sudan namely, Usher Calotropis procera, Argel, Solenostemma argel, and Datura, Datura stramonium. The results showed that, all plant materials had varying degrees of insecticidal activity, and the ability of the three plants extracts (aqueous, ethanol and powder) to cause effects on the Saw-toothed grain beetle on dates can be attributed mainly to contact toxicity.

Usher: the mortality effect of usher becomes a well documented fact with the three conditions, powder (Table 1), water extract (Table 2) and ethanol extract (Table 3). The three concentrations of Usher leaves at the three conditions revealed that, mortality of the Saw- toothed grain beetle was affected by the time and increase in concentration. The study agreed with Shah et al. [16] and Shah et al. [17] who mentioned that, the extracts of six plants had toxicity and repellency effects against the sawtoothed grain beetle, Oryzaephilus surinamensis (L.). The rate of repellency increased with increase in the 4 concentrations applied. Similarly, these finding agreed with Saghee etal. [15] who stated that the mortality of $T$. castaneum increased with both an increase of concentration of 4 plant extracts as well as exposure time of treatment.

Argel: The results of treatments with Argel extracts shown in tables (1,2 and 3) also indicated that, the high mean numbers of adult mortality were caused by the leaves' powder and ethanol extracts. Generally, there was no significant difference between percentage mortality caused by the three extracts. However, there was a significant difference between treatments and control mortality. The results of a study by Neetu et al. [14] showed that the extracts of 4 plants and their combinations controlled $O$. surinamensis by showing repellent behavior. Al Qahtani et al. [4] mentioned that, the extracts of 3 tested plants, (ginger, Zingiber afficinale; hail, Elettaria cardamomum; and shammar, Foeniculum vulgare, showed insecticidal activity against $O$. surinamenss, and indicated that, Ginger was the most potent plant, recording the lowest $\mathrm{LC}_{50}$ value $(0.14 \mathrm{mg} / \mathrm{g})$ followed by hail and shammar $\left(\mathrm{LC}_{50}=0.4\right.$ and $0.7 \mathrm{mg} / \mathrm{g}$ ) respectively .Similar results were obtained by
Yousif and Satti [21] who showed inferior insecticidal effect from S.argel against $T$. granarium larvae, as compared with other six plants. Also, similar findings were reported by Mahmoud et al. [12] who investigated the effects of four plants, neem $A$. indica (seeds), Usher $C$. procera (leaves), Argel S. argel (leaves) and scorpion root, Aristolochia bracteolate (shoots). The results of the bioassay showed that, all the plants have insecticidal effects on the T. granarium with variable levels. The current results also agree to some extent with Bakhiet and Taha [8] regarding the effect of $S$. argel on the adult of faba bean beetle, Bruchidius incarnatus.

Datura: Analysis of data of the mortality caused by treatments with $D$. stramonium extracts shown in tables (1, 2 and 3) indicated that, generally no variation in percentage mortality was noticed between the different concentrations of the 3 extracts. However, there was a significant difference in adult mortality between treatments and control. The three concentrations of the plant revealed that, the mortality of the insect was affected by increase in time. Similar results were reported by Farkhanda et al.[10] who showed the effects of ethanol extracts of five plants' leaves, Bakain (Melia azedarach), Mint (Mentha longifolia), Habulas (Myrtus communis), Lemongrass (Cymbopogon citrates) and Datura (D.stramonium). The extracts were mixed with $10 \mathrm{mg} / \mathrm{g}$ of grains, and comparison of the plant extracts on $O$. surinamensis showed that, Habulas extracts were the most effective causing $50.71 \%$ mortality, whlie Datura showed maximum mortality of (21.43\%). Also, Malgorzata and Anna [13] mentioned that the powdered plants of different species namely: peppermint, Mentha piperita(L.); wormwood Artemisia absinthium (L.); common sage, Salvia officinalis (L.), allspice Pimenta dioica and common garlic Allium sativum(L.), added to semolina using 3 concentrations, influenced the mortality rate in the saw-toothed grain beetle by different degrees, with allspice seeds caused the highest mortality. These results are also in agreement with Abid etal., [1] who assessed the contact toxicity and the trans-generational effect of $D$. alba leaf extract against two important stored insect pests of Rice, T. granarium and $S$. oryzae, under laboratory conditions. The highest concentration $(2.5 \%)$ induced significantly high mortality of 33.5 and $45 \%$ in $T$. granarium and $S$. oryzae after 7 days of exposure, respectively.

\section{Conclusions}

It was evident from this study that, all plants tested have the potential of being used as Biopesticides. The results therefore strongly suggest the possibility of using extracts of the three plants (Usher, Argel, Datura) effectively against the Saw-toothed grain beetle on stored dates. In addition,more investigation are also needed to identify other local plant materials of insecticidal activity against the disturbing infestation of Oryzaephilus surinamensis in dates' stores. 


\section{REFERENCES}

[1] Abid, A. Farooq, A.; Antonio, B.; Yash, W. and Nicolas, D. (2012). Potential for using Datura alba leaf extracts against two major stored grain pests, the Khapra beetle, Trogoderma granarium and the Rice weevil, Sitophillus oryzae. J. Pest. Sci., 85: 359-366.

[2] Adedire, C.O. \&Ajaji, T. S. (1996). Assessment of the insecticidal properties of some plant extracts as grain protectants against the maize weevil, Sitophilus zeamais. Nigerian Journal of Entomology, 13:93-101.

[3] Ahmed, G. A. (1993). Preliminary investigation in the insecticidal potentialities of Usher plant. Calotropis procera Ait, M. Sc. Thesis, Fac. Agric., Univ. of Khartoum, Sudan.

[4] Al Qahtani, A. M.; AI- Dhafar, Rady. M. H. (2012) ). Insecticidal andbiochemical effect of some dried plants against Oryzaephilus surinamensis (Coleoptera: Silvanidae ) Journal of Bazic\& Applied Zoology, Volume 56: 88-93

[5] Ajayi, F. and Lale, N. E. S. (2001). Susceptibility of unprotected seeds and seeds of local bambara groundnut cultivars protected with insecticidal essential oils to infestation by Callosobruchus maculatus (F). Journal of Stored Products Research, 37: 47-62.

[6] Akinkurolere, R. O.; Adedire, C. O and O. deyemi, O. O. (2006). Laboratory evaluation of the toxic properties of forest Anchomanes, Anchomanes difformis against pulse beetle, Callosobruchus maculatus( Coleoptera: Bruchidae ). Insect Sci., 13:25-29

[7] Ascher, K. R. S (1981). Some physical (Solubility) properties and biological (Sterilized for Epilachna varieties females) Effect of dried methanolic neem (A. indica) seed kernel extract. Proc $.1^{\text {st }}$ Neem conf $63-74$

[8] Bakhiet, E. H and Taha, A. K. (2009). Effect of leaves powder and aqueous extracts of periwinkle (Vinca rosea L ) and Argel (Solenstemma argel) (Del ), Hayne on the adults of the faba bean beetle Bruchidius incarnatus (Boh.) (Coleoptera: Bruchidae). Journal of Science and Technology, 10 (3): 135-154.

[9] Fatope , M. O. Mann, A. Takeda, Y. (1995). Cowpea weevil bioassay: A simple prescreen for plants with grain protectant effects. International Journal of Pest Management, 41: 44-46.

[10] Farkhanda, M. Ghazala, N. S, Saadiya, A. M. (2011). Effect of ethanolic Plant Extracts on three storage grain pests of economic importance. Pak. J. Bot., 43(6): 2941- 2946.
[11] Kim, S. I, Roh J. Y, Kim D. H, Lee H. S and Ahn Y.J (2003).Insecticide activities of aromatic plant extracts and essential oils against Sitophilus oryzae and Callosobruchus chinensis. J. Stored Prod. Res. 39: 293-303.

[12] Mahmoud, A. K; Bedawi, S. M. and Satti, A., A. (2015). Efficacy of some Botanical Extracts in the control of Khapra Beetle (Trogoderma granarium). Journal of Science / vol 5 / Issue 4 /213-217.

[13] Malgorzata, K. and Anna, P. (2015). The mortality of Oryzaephilus surinamensis Linnaeus, (Coleoptera: Silvanidae ) induced by powdered plants. Journal of Plant Protection Research Vol. 55, No.1: 110-116.

[14] Neetu, K. Geeta D. M and Shashi, M. (2015). Plant extracts controls Oryzaephilus surinamensis by showing repellency behavior. European Journal of Experimental Biology, 5(5): 98-101.

[15] Saghee, M. Mansoor-ul-Hasanl, Latif, M. A and Igbal, J, (2011). Evaluation of some indigenous medicinal plants as a source of toxicant, repellent and growth inhibitors against Tribolium castaneum(Coleoptera: Tenebrionidae). Pakistan Entomologist; 33: 87-91

[16] Shah, M. M. R \&Shahjahan, M. (2006). Toxicity Effect of Some Indigenous Plant Extracts against Saw - Toothed Grain Beetle, Oryzaephilus surinamensis (L) (Coleoptera: Silvanidae). Bangladesh J. Entomol.16 (1): 57-66.

[17] Shah, M. M. R, Prodhan, M. D. H, Siddguie, M. N. A, Mamun, M. A. A and Shahjahan, M. (2008). Repellent Effect of Some Indigenous plant Extracts against Saw Toothed Grain Beetle, Oryzaephilus surinamensis (L) International Journal of Sustainable Crop Prod., 3 (5): 51-54.

[18] Sidahmed, O. A. A. (2006). Field control of the white scale insect, Parlatoria blanchardii (Targ) (Homoptera; Diaspididae ) with aqueous extracts of Argel (Solenostemma argel) (Del.) Hayne. M. Sc. Thesis, Sudan University of Science and Technology, Pp (61).

[19] Siddig, S. A. (1990). Recommendation of neem (Azadirachta indica A, juss) for the control of vegetable pests infestation. Paper prepared for the approval of the National Pests and Diseases Committee, ARC, Wad Madani .

[20] Sousa, A. H; Maracaja, P; Silva, R. M. A; Moura, M. N .and Andrade, W. G. (2005). Bioactivity of vegetable powder against Callosobruchus maculatus (Coleoptera: Bruchidae ). Revista De Biologia E Ciencias Da Terra ISSN1519 -5228.

[21] Yosif, E. A. A and Satti, A. A. (2014). Evaluation of water extracts from seven Sudanese plants as natural insecticides. International Journal of Science and Research, 3 (12): 1305 1310 